\title{
Aplicação do Índice "Relação Declividade-Extensão - RDE" na Bacia do Rio do Peixe (SP) para Detecção de Deformações Neotectônicas
}

\author{
Mario Lincoln Etchebehere' (metchebehere@ung.br), Antonio Roberto Saad ${ }^{1,2}$, \\ Vicente José Fulfaro',2, José Alexandre de Jesus Perinotto ${ }^{1,2}$ \\ 'Centro de Pós-Graduação, Pesquisa e Extensão - UnG \\ Praça Tereza Cristina 1, CEP 07023-070, Guarulhos, SP, BRA \\ ${ }^{2}$ Departamento de Geologia Aplicada - Instituto de Geociências e Ciências Exatas - UNESP, Rio Claro, SP, BRA
}

Palavras-chave: morfometria fluvial, neotectônica, gradiente hidráulico.

\section{RESUMO}

Este trabalho apresenta a aplicação do índice RDE (Relação Declividade-Extensão) para a identificação de regiões sujeitas a deformações tectônicas ao longo da bacia hidrográfica do Rio do Peixe, região ocidental paulista. Parte-se da premissa de que os cursos d'água representam os elementos mais apropriados para este tipo de análise por se ajustarem rapidamente a deformações crustais, mesmo àquelas muito sutis, gerando modificações perceptíveis em seus parâmetros morfométricos. Técnicas como esta são particularmente úteis em áreas como o oeste paulista, caracterizadas por apresentarem relevo suave e profundo intemperismo químico, que resultam espessos regolitos e raros afloramentos. O índice RDE é calculado como sendo a razão entre a amplitude altimétrica de cada curso d'água e o logaritmo natural de sua extensão. Os valores obtidos podem ser plotados em mapa (no ponto mediano de cada drenagem), possibilitando o traçado de linhas de isovalores (isodefs). No caso do vale do Rio do Peixe, foram delineadas três principais anomalias (A, B e C), que representam áreas em processo de soerguimento, o que condiciona reflexos na formação e distribuição dos depósitos neoquaternários como os terraços, aluviões atuais e, possivelmente, leques aluviais hodiernos. Com base nos dados tectônicos disponíveis para esta região, pode-se atrelar as anomalias A e B respectivamente às suturas crustais Ribeirão Preto e Presidente Prudente; a anomalia C, de menor porte, ainda carece de maiores informações de campo, podendo estar associada com a sutura crustal Três Lagoas. Vale lembrar que estas suturas são feições herdadas do embasamento pré-cambriano, e que apresentam reflexos em toda a pilha sedimentar e ígnea da Bacia do Paraná, como também no traçado de lineamentos, sendo sugestivas da atuação de uma tectônica de caráter ressurgente.

Keywords: fluvial morphometry, neotectonics, hydraulic gradient.

\section{ABSTRACT}

This paper presents the identification of tectonic deformation through the application of the stream-gradient index (slope x length) method in the Rio do Peixe hydrographic basin, located in western State of São Paulo. The main principle used is that river valleys are the best tools for this type of analysis because of their fast adjustment to even the most gentle crustal deformations. This type of analysis for structural studies is extremely useful in the western region of the State of São Paulo, where deep chemical weathering results in a thick regolith and scarce outcrops. The stream length index is the ratio of the altimetric amplitude of each drainage and the natural logarithm of its length. The value obtained is plotted on maps at the median point of each drainage, allowing the drawings of lines with the same values (isodefs). Three anomalies (A, B and C) were identified along the Rio do Peixe valley representing uplift sectors indicated by the formation and distribution of Upper Quaternary deposits in terraces and modern fluvial plains and alluvial fans. In correlation with known tectonic data for this region it is possible to attribute the A and B anomalies to the Ribeirão Preto and Presidente Prudente crustal sutures, respectively. The smaller $\mathrm{C}$ anomaly needs further field investigation, but it could be associated with the Três Lagoas crustal suture. It must be emphasised that these sutures are inherited from the Precambrian Basement which had a strong influence on the Phanerozoic evolution in the whole sedimentary and volcanic stratigraphic pile of the Paraná Basin and on the dominant structural lineaments directions developed therein. The A, B and C anomalies are suggestive of renewed uplift as a result of neotectonic action in modern times. 


\section{INTRODUÇÃO}

Os cursos d'água são considerados os elementos mais sensíveis às modificações tectônicas crustais, respondendo de imediato a processos deformativos, mesmo àqueles de pequenas escalas e magnitudes (Volkov et al., 1967; Ouchi, 1985; Phillips e Schumm, 1987; Schumm, 1993; Wescott, 1993). Tais características os tornam elementos apropriados a análises de cunho neotectônico, buscando determinar áreas sujeitas a movimentações, permitindo, inclusive, avançar em termos quantitativos acerca destas deformações.

A identificação de evidências de atividade neotectônica em terrenos do interior continental, onde o registro da sismicidade seja pobre ou as deformações crustais sejam assísmicas, ainda pode ser classificada como um esforço heurístico. Nesse sentido, as técnicas morfométricas que exploram atributos relacionados aos perfis ou ao traçado dos cursos d'água apresentam um potencial relativamente elevado para a detecção e a avaliação de deformações. Assim, apresenta-se, neste trabalho, a aplicação da técnica denominada "Relação Declividade-Extensão - RDE", também conhecida como "Índice de Hack", para a detecção de deformações crustais a partir do estudo deste parâmetro morfométrico na bacia de drenagem do Rio do Peixe, região ocidental do Estado de São Paulo.
Esta técnica possibilita uma avaliação rápida, eficaz e de baixo custo acerca do quadro neotectônico da região, servindo de modelo de aplicação regional para áreas de interior cratônico. Da mesma forma, este enfoque alternativo pode se somar a outras abordagens (geodésicas, geofísicas, geotécnicas, geológicas e geomorfológicas), contribuindo para o aprimoramento de análises neotectônicas - em uma linha de "convergência de evidências" - tornando os modelos e as interpretações mais consistentes, especialmente para regiões intraplacas como é o caso da maior parte do território brasileiro.

\section{A ÁREA DE ESTUDO}

A área investigada corresponde à bacia hidrográfica do Rio do Peixe, inserida no chamado Planalto Ocidental Paulista, entidade geomorfológica definida por Moraes Rego (1932). A localização da área de estudo é mostrada na Figura 1.

A bacia hidrográfica do Rio do Peixe compreende uma área total de $12.393 \mathrm{~km}^{2}$, distribuídos por territórios de 26 municípios, com destaque para as cidades de Marília, Osvaldo Cruz, Adamantina, Presidente Prudente, Tupã, Bastos, Junqueirópolis, Martinópolis, Piquerobi, Lutécia, Oscar Bressane, Oriente e Garça (SMA, 1997). Tais localida-

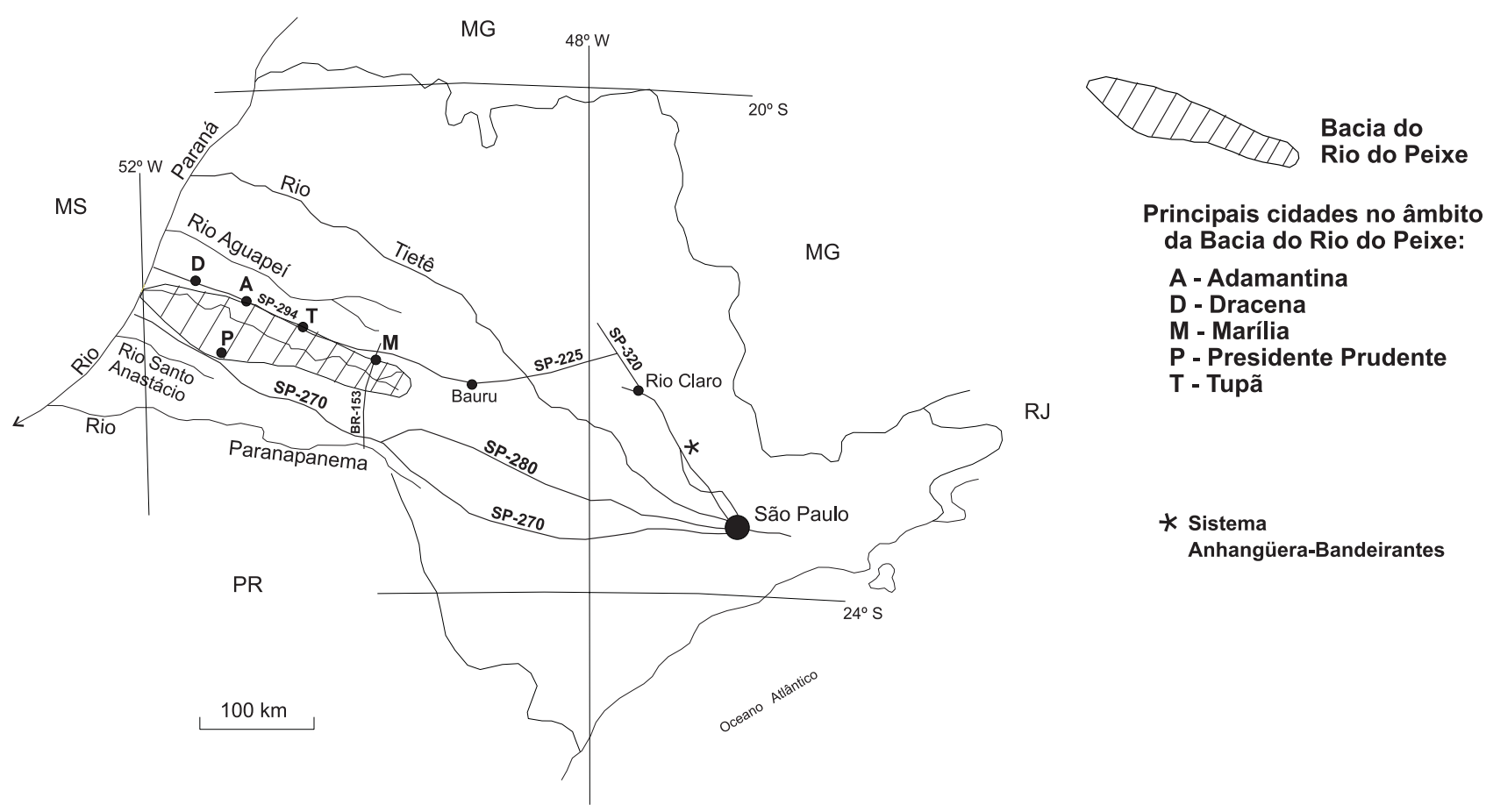

Figura 1. Localização da bacia do Rio do Peixe no Estado de São Paulo e principais vias de acesso à área de estudo. 
des, na maior parte dos casos, ocupam os espigões que dividem o vale do Rio do Peixe com as bacias limítrofes do rio Santo Anastácio, ao sul, e Aguapeí ou Feio, ao norte. Raras são as localidades situadas próximas à região ribeirinha, sendo que o distrito de Varpa (Município de Tupã) constitui a mais notável exceção, plantado que está junto à barranca direita do Rio do Peixe. A disposição destes núcleos urbanos decorre da ocupação histórica da região, que se deu no início do séc. XX, com o rápido avanço da cultura cafeeira, que ocupava os espigões, por onde também foram dispostos os grandes ramos ferroviários da região ocidental paulista.

O Rio do Peixe apresenta uma extensão total de $398 \mathrm{~km}$, ao longo de um vale de aproximadamente $250 \mathrm{~km}$ de comprimento; a vazão média do rio, na foz, é da ordem de $91 \mathrm{~m}^{3} / \mathrm{s}$ (DAEE, 1979). Seus maiores afluentes são os ribeirões Taquaruçú, do Mandaguari e dos Guachos, todos da margem esquerda; a propósito, mais ampla que a vertente setentrional, o que configura uma notável assimetria, particularmente nos trechos médio e inferior da bacia do Rio do Peixe.

$\mathrm{O}$ vale do Rio do Peixe pode funcionar como uma adequada área-teste devido ao fato de ali terem sido detectados indícios de deformações tectônicas recentes, tais como: diversas gerações de depósitos de terraço, holocenos e pleistocenos, indicando mudanças significativas de níveis de base; falhas afetando esses depósitos (Etchebehere, 1996, 1999, 2000; Etchebehere e Saad, 2002); lineamentos seccionando aluviões atuais, conforme já observado por Riccomini (1995); presença de freqüentes estruturas de liquefação, indicativas de origem sísmica (Etchebehere et al., 1998; Etchebehere e Saad, 2002); bem como diversas feições de capturas de drenagem em interflúvios limítrofes da bacia (Justus, 1985; IPT, 1992). Destaque-se, também, que outros indícios de atividade neotectônica em diversos trechos do Rio do Peixe têm sido reportados na literatura geológica abrangendo esta região, (e.g., Nakasu, 1998), além do fato de que parte desta bacia situa-se na região sismogênica de Presidente Prudente ( $c f$. Mioto, 1993, 1996).

\section{CONTEXTOS GEOLÓGICO E TECTÔNICO}

A bacia do Rio do Peixe tem como substrato rochas sedimentares cretáceas dos grupos Bauru e Caiuá (senso Fulfaro e Barcelos, 1993; Fulfaro et al., 1999) e esporádicas e localizadas ocorrências de basaltos da Formação Serra Geral. Capeando essas unidades cretáceas, ocorrem depósitos de terraços pleistocenos, enfeixados na Aloformação Rio do Peixe (Etchebehere, 2000), bem como alúvios, colúvios, leques aluviais, e elúvios (em remanescentes de superfícies sedimentares), sem designações estratigráficas formais.

Em termos geomorfológicos, a região abarcada pela bacia do Rio do Peixe exibe dois principais níveis planálticos, quais sejam: o dos planaltos de Marília e Exaporã, elevando-se entre 600 - $750 \mathrm{~m}$ de altitude, e o setor de planaltos rebaixados, com altitudes variando de 550 a $250 \mathrm{~m}$, com diminuição das cotas rumo à calha do rio Paraná. Modelados de acumulação acham-se restritos a planícies aluvionares do Rio do Peixe e baixos cursos dos principais afluentes, com destaque para o trecho inferior da bacia.

O contexto tectônico da área estudada pode ser delineado com base nos trabalhos desenvolvidos no âmbito da Bacia Sedimentar do Paraná no Estado de São Paulo. De acordo com estudos desenvolvidos pelo IPT (1989), o Estado de São Paulo acha-se compartimentado por dois principais tipos de descontinuidades crustais, designados suturas e lineamentos. Estas feições estruturais foram demarcadas principalmente com base em dados geofísicos (gravimetria, aeromagnetometria e sondagens magnetotelúricas). Segundo o IPT (op. cit.), essas descontinuidades crustais configurariam feições herdadas do embasamento cristalino.

Posteriormente, Saad (1997) comparou os resultados anteriormente obtidos com dois outros tipos de dados, a saber: traços em imagens de sensores remotos, objetivando verificar aqueles elementos estruturais com expressão em superfície, e estratigráficos em âmbito bacinal, por meio da disposição de isópacas e mapas de contornos estruturais, no intuito de determinar a influência desses mesmos elementos na sedimentação e preservação das seqüências ordovício-silurianas a neocretáceas da Bacia Sedimentar do Paraná.

Riccomini (1997) apresentou um quadro da tectônica deformadora da Bacia Bauru que pode auxiliar no entendimento dos fenômenos aqui descritos. Este autor mencionou observações de campo e análises de estruturas que mostrariam que as atitudes das falhas mais jovens, cortando colúvios, depósitos de terraços fluviais e stone lines, seriam, em parte, coincidentes com a de juntas pré-existentes, podendo representar reativações destas. $\mathrm{O}$ tectonismo deformador pode ser interpretado como resultante de dois regimes transcorrentes, o primeiro com $\sigma 1 \mathrm{EW} /$ horizontal, $\sigma 2$ vertical e $\sigma 3 \mathrm{NS} /$ horizontal, e o posterior com $\sigma 1 \mathrm{NS} /$ horizontal, $\sigma 2$ vertical e $\sigma 3 \mathrm{EW} /$ horizontal, correlacionáveis à megaestruturação do Estado de São Paulo, sendo o último vinculado à atividade neotectônica regional. A Figura 2 contempla estas duas proposições.

$\mathrm{Na}$ área de estudo, destacam-se as suturas crustais Presidente Prudente, Ribeirão Preto e Três Lagoas, de direções nordeste, e os lineamentos Guapiara e Marília, de direções noroeste. Admite-se que esses elementos foram palcos de movimentações tectônicas ao longo do Fanerozóico, com 


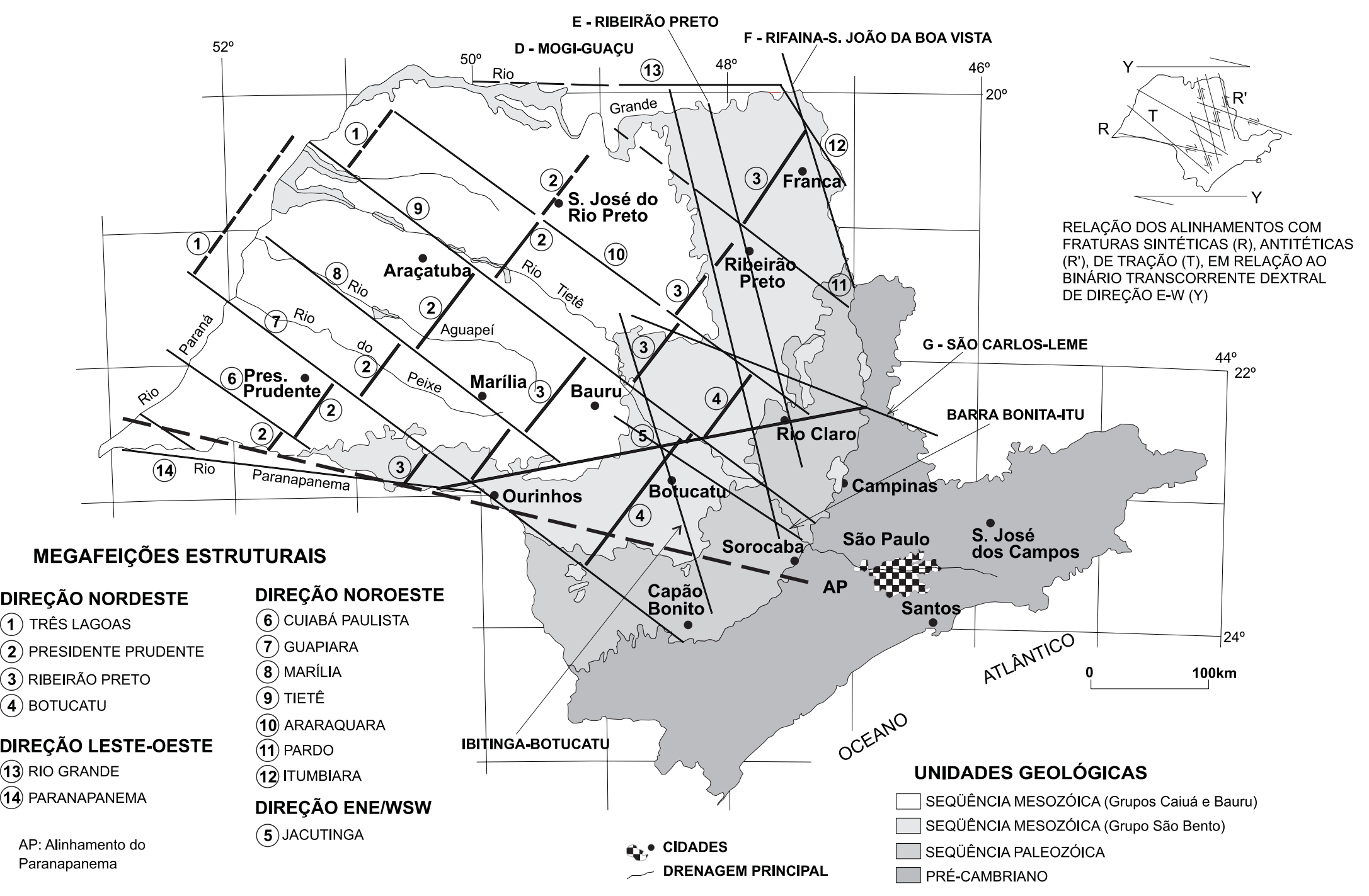

Figura 2. Principais elementos estruturais da Bacia do Paraná no Estado de São Paulo. Modificado de Saad (1997) e Riccomini (1997). 
reflexos na sedimentação e preservação de toda a pilha sedimentar, ensejando a existência de uma tectônica ressurgente, conforme conceito expresso por Hasui (1990).

\section{ANÁLISES FLÚVIO-MORFOMÉTRICAS}

\section{Generalidades}

A análise de padrões de drenagem para identificar estruturas geológicas tem sido uma técnica comumente utilizada por geomorfólogos e fotointérpretes. Nesse sentido, podese mencionar, entre outros, os trabalhos pioneiros de Zernits (1932); Horton (1945); Strahler (1952a, b); Howard (1967) e Rivereau (1969). Estas contribuições serviram como ponto de partida para diversas outras abordagens analíticas aplicáveis ao estudo das características das redes de drenagem, com implicações para o conhecimento sobre a evolução da paisagem, para a definição do substrato geológico, para se delinear feições morfoestruturais, e, mais recentemente, também para a detecção de deformações neotectônicas.

Uma ampla revisão bibliográfica sobre análises morfométricas foi realizada por Christofoletti (1969), abordando longa série de parâmetros das redes de drenagem, incluindo índices e relações lineares, em áreas, e altitudinais. Contudo, todos estes elementos morfométricos foram aplicados mais à interpretação das características físicas do substrato geológico sulcado pelas drenagens (composição lítica + condicionantes estruturais) do que sobre eventuais implicações tectônicas. Uma visão um pouco mais abrangente, que envolve a neotectônica, pode ser vista na contribuição de Deffontaines e Chorowicz (1991), com exemplo de aplicação prática no território do Zaire.

Considera-se oportuno abrir aqui um parêntese, de maneira a diferenciar adequadamente os conceitos de feições morfoestruturais e de feições morfotectônicas. No entendimento dos autores deste trabalho, o termo "morfoestrutural" abrange aquelas feições passivas, eventualmente resultantes de uma deformação pretérita, e sobre cuja geometria os cursos d'água podem se amoldar, fazendo com que o padrão local da rede de drenagem reflita a disposição dos corpos rochosos, i. e. do arranjo e da atitude de seus estratos e/ou de suas feições estruturais. Já no que se refere a "feições morfotectônicas", fica patente um liame entre a acomodação dos elementos da rede de drenagem e as deformações crustais síncronas, estabelecendo, assim, um caráter "ativo" para as feições prenunciadas, igualmente passíveis de detecção e mensuração.

Em termos estritamente morfotectônicos, consideramse como marcos na análise de parâmetros morfométricos das redes de drenagem, os trabalhos de Volkov et al. (1967); Bjornberg (1969a, b); Hack (1973); Burnett e Schumm (1983);
Bjornberg (1992); Mayer (1992); Marple e Talwani (1993); Merrits e Hesterberg (1994); Boyd e Schumm (1995); Schumm e Spitz (1996); Spitz e Schumm (1997). Após diversos anos estudando perfis longitudinais de rios, Hack (op. cit.) propôs um novo índice para detectar alterações no curso, decorrentes de mudanças no substrato geológico, aporte de carga, ou tectonismo, chamado de stream-gradient index, ou simplesmente índice SL (relação declive (slope) vs. comprimento de curso (length)), aqui traduzido como Relação Declividade-Extensão de curso (RDE). Este índice foi aplicado, com sucesso, na definição de fenômenos neotectônicos em diversos contextos geológicos, tais como nos Himalaias (Seeber e Gornitz, 1983); no nordeste de Arkansas e sul do Missouri (USA), próximo à zona sismogênica de New Madrid (McKeown et al., 1988); junto à falha de San Andreas, na Califórnia (USA), no limite tríplice entre as placas tectônicas Norte-Americana, do Pacífico e Gorda (Merritts e Vincent, 1989); e na região de Charleston (South Carolina, USA) onde se registrou um terremoto em 1886 com $M_{b}=6,6-6,9$, resultado da movimentação de uma falha cega (Falha Woodstock - Rhea, 1989; Marple e Talwani, 1993). No território brasileiro já existem registros de aplicação de técnicas semelhantes, como na região amazônica (Rodriguez e Suguio, 1992; Rodriguez, 1993) e na Bacia Sedimentar de São Paulo (Takiya, 1997).

\section{Perfis longitudinais dos rios}

Uma das representações mais freqüentes de aspectos morfométricos de cursos d'água refere-se a perfis longitudinais de rios, plotados em gráficos de coordenadas cartesianas, considerando-se como variável dependente a altitude dos diversos pontos da drenagem. No eixo das abscissas, costuma-se lançar a extensão do rio, com origem posicionada na cabeceira ou na foz do mesmo (Figura 3 ).

Como pode ser visto na Figura 3, em geral este gráfico mostra curvas de conformação logarítmica, concavidade para cima, e assíntotas longas. Acredita-se que quanto mais equilibrado (graded) for o curso d'água, mais ajustado a este tipo de equação será o seu perfil. Vale lembrar que a conceituação de curso equilibrado (graded stream) seria, conforme Mackin (1948), a seguinte:

"The graded stream is one in which, over a period of years, slope is delicately adjusted to provide, with available discharge and with prevailing channel characteristics, just the velocity required for the transportation of the load supplied from the drainage basin. The graded stream is a system in equilibrium, its diagnostic characteristic is that any change in any of the controlling factors will cause a displacement of the equilibrium in a direction that will tend to absorb the effect of the change."

Leopold e Bull (1979) formalizaram o conceito de equilí- 

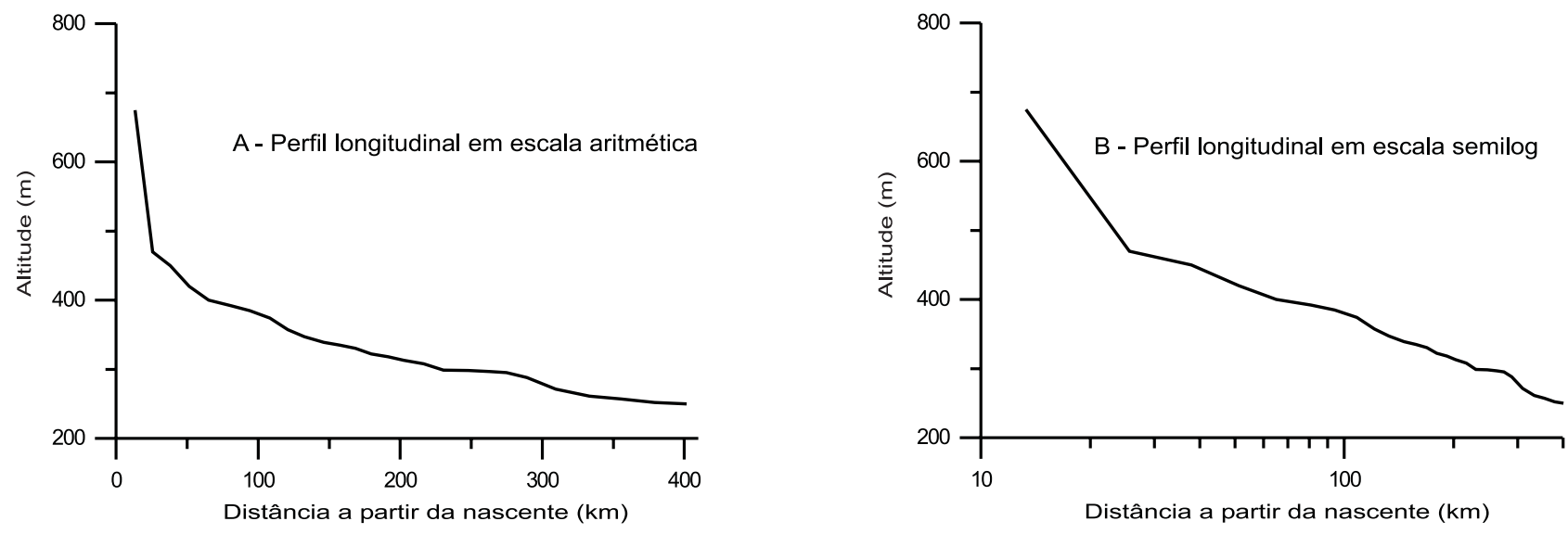

Figura 3. Perfis longitudinais do Rio do Peixe: as "rugosidades" observadas indicam possíveis anomalias tectônicas.

brio como sendo:

“... one in which, over a period of years, slope, velocity, depth, width, roughness, pattern, and channel morphology delicately, and mutually adjust to provide the power and efficiency necessary to transport the load supplied from the drainage basin without aggravations or degradation of the channels."

Em síntese, para os propósitos do presente estudo, considera-se que uma determinada drenagem ou trechos da mesma poderão ser considerados em equilíbrio quando não se verificar agradação ou entalhe do talvelgue, havendo, tão somente fluxo da carga sedimentar (bypassing process). Conforme enfatizado por McKeown et al. (1988), o formato do perfil longitudinal de um curso d'água que esteja em equilíbrio (graded) apresenta a típica forma côncava, que pode ser descrita por uma equação exponencial; qualquer alteração no perfil leva a corrente a se ajustar na busca de um novo equilíbrio, seja erodindo seu próprio leito, seja propiciando agradação. Curvas com menor concavidade indicariam condições de desequilíbrio. O tempo necessário para que a drenagem readquira o equilíbrio ou, ao menos, um estágio de quasi-equilibrium não pode ser precisado, embora alguns autores admitam-no como pequeno em termos geológicos (e. g. Hack, 1960; Leopold e Langbein, 1962). A prevalecer este ponto de vista, trechos de drenagem fora de equilíbrio podem ser indicativos de atividade tectônica recente.

Voltando a atenção para a Figura 3, desenho A, pode-se observar que a curva ali disposta apresenta geometria, como dito, mais ou menos afeiçoada a uma equação logarítmica, apresentando pequenas quebras ou rupturas na linha de declividade. Estas quebras devem representar processos que estão alterando o equilíbrio do curso d'água nestes setores. Geralmente, estes desequilíbrios estão ligados ou a confluências de tributários, ou a heterogeneidades no substrato rochoso, ou ainda a processos de deformação crustal.

Outra forma de representação usual é aquela onde o comprimento do rio é lançado em escala logarítmica (gráfico semilog - Figura 3, desenho B), produzindo uma reta, ao menos para o trecho situado abaixo das cabeceiras, onde a declividade geralmente é menos acentuada. Neste caso, a "rugosidade" desta reta deve estar relacionada a algum fator de desequilíbrio mencionado no parágrafo anterior. Este foi o princípio aplicado por Volkov et al. (1967), que estudaram a plataforma russa buscando detectar movimentos crustais mediante aplicação de equações matemáticas das parábolas que melhor se ajustassem aos perfis longitudinais dos rios. Os trechos anômalos representavam segmentos de curva com maior afastamento, positivo ou negativo, em relação ao perfil longitudinal de cada curso d'água, o que permitiria estabelecer, inclusive, valores de isodeformação (isodefs). Outros modelos matemáticos de perfis fluviais considerados em equilíbrio (graded) foram estabelecidos por Snow e Slingerland (1987); neste caso, os desajustes em relação à função de melhor ajuste seria um indicativo de que o equilíbrio fora rompido e que disto decorreriam alterações morfométricas.

Um ponto passível de discussão deste enfoque referese justamente à equação que representa o perfil teórico do curso d'água. Considera-se discutível o expoente a ser utilizado na parábola, bem como a própria escolha deste tipo de curva. Vale lembrar a análise efetuada por Tanner (1971), ao estudar equações que poderiam matematicamente representar perfis fluviais, que concluiu não existir uma curva completamente satisfatória para todo tipo de perfil. Na realidade, talvez nem fosse possível ajustar todo o perfil de um rio em uma única equação, devendo cada trecho ser repre- 
sentado por sua própria curva (perfil composto no sentido de Shepherd, 1985).

\section{RELAÇÃO DECLIVIDADE-EXTENSÃO DE CURSO D'ÁGUA (RDE)}

\section{Princípios e técnicas}

Este método foi estabelecido, como já mencionado, por Hack (1973), resultando em um índice que possibilita a análise de perfis longitudinais de rios e de trechos selecionados, propiciando as bases para o estabelecimento de comparações entre cursos d'água de ordem e de porte diferentes. Originalmente designado stream-gradient index, ou simplesmente índice SL (relação slope vs. length), na medida em que se refere à declividade de um determinado trecho de um rio normalizada pela distância do referido trecho às cabeceiras, este parâmetro não deve ser confundido com o gradiente da drenagem, que é simplesmente a razão entre a diferença altimétrica entre dois pontos distintos do curso e a distância entre ambos. Ou seja, é errôneo traduzi-lo simplesmente como gradiente hidráulico, como fizeram alguns autores brasileiros (e. g., Rodriguez e Suguio, 1992; Rodriguez, 1993; Takiya, 1997).

O índice RDE pode ser calculado da seguinte forma:

$$
\mathrm{RDE}=(\Delta \mathrm{h} / \Delta \mathrm{l}) . \mathrm{L}
$$

onde, $\Delta \mathrm{h}$ é a diferença altimétrica entre dois pontos extremos de um segmento ao longo do curso d'água; $\Delta \mathrm{l}$ é a projeção horizontal da extensão do referido segmento (i. e., $\Delta \mathrm{h} / \Delta \mathrm{l}$ corresponde ao gradiente da drenagem naquele trecho); e L corresponde ao comprimento total do curso d'água a montante do ponto para o qual o índice RDE está sendo calculado. A Figura 4 possibilita um entendimento mais claro de como pode ser calculado o índice RDE para um determinado trecho de drenagem.

O índice RDE pode ser calculado para toda a extensão de um rio ("whole" slope vs. length index), considerandose a amplitude altimétrica total, ou seja, a diferença topográfica (em metros) entre a cota da cabeceira e a cota da foz, e o logaritmo natural da extensão total do mesmo, conforme sugerido por McKeown et al. (1988), e como aplicado no presente trabalho de análise tectônica da bacia do Rio do Peixe. Os índices RDEs aplicados a segmentos de drenagem têm conotação mais local, aplicando-se a análises tectônicas de detalhe, conforme será abordado em outra contribuição (Etchebehere et al., em preparação). Pode-se adiantar, todavia, que até mesmo relações entre índices locais $\left(\mathrm{RDE}_{\text {trecho }}\right)$ e índices de toda a extensão da drenagem $\left(\mathrm{RDE}_{\text {total }}\right)$ podem ser estabelecidas para se categorizar os valores calculados em classes de interesse à interpretação geológica, tal como pro-

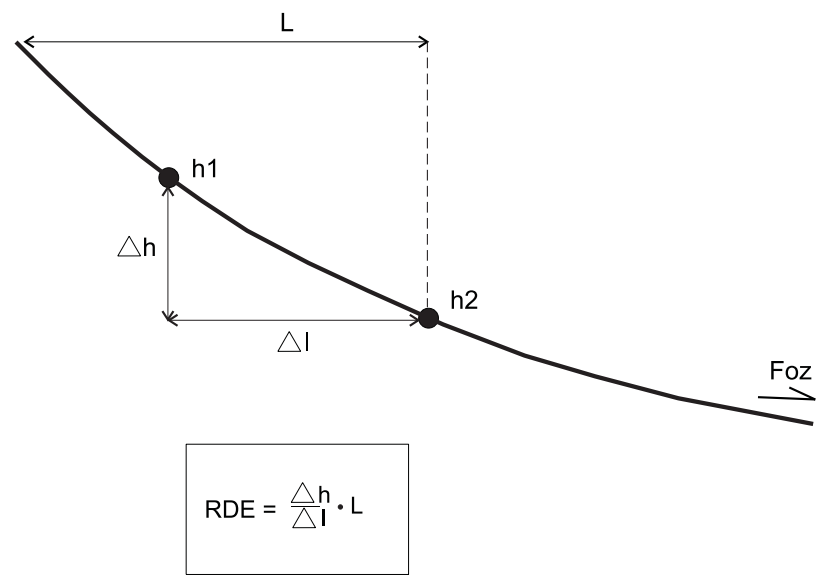

Figura 4. Parâmetros utilizados no cálculo do índice RDE para segmento de drenagem (intervalo entre duas isoípsas consecutivas). $\mathrm{L}=$ comprimento da drenagem entre a cabeceira e a isoípsa jusante; $\Delta \mathbf{h}=$ diferença de altitude entre duas isoípsas subseqüentes; $\Delta \mathbf{l}=$ projeção horizontal do comprimento do segmento de drenagem entre duas isoípsas subseqüentes. Extraído de Etchebehere (2000).

cederam Seeber e Gornitz (1983) para análises tectônicas na cordilheira himalaiana.

É importante salientar que os índices RDEs se correlacionam com os níveis de energia da corrente (stream power), refletida na capacidade de erodir o substrato e de transportar a carga sedimentar. Conforme destacado por Keller e Pinter (1996, p. 129), esta energia é proporcional à declividade da superfície por onde flui o curso d'água (o gradiente) e à descarga (volume) do mesmo naquele trecho, este segundo fator sendo considerado diretamente proporcional ao comprimento da drenagem.

Os procedimentos adotados para se calcular o índice $\mathrm{RDE}_{\text {total }}$ na bacia do Rio do Peixe foram os seguintes:

a. selecionaram-se os cursos d'água de porte mais expressivo nas folhas topográficas em escala 1:50.000, adotando-se como critério aquelas drenagens com extensão superior a $15 \mathrm{~km}$ na maior parte dos casos, independentemente da hierarquia fluvial (Figura 5);

b. mediu-se, com o auxílio de um curvímetro, o comprimento de cada drenagem escolhida, baseando-se no traçado das linhas azuis das referidas cartas. Os valores obtidos (diferença altimétrica e comprimento do curso d'água) foram tabulados e lançados em uma planilha eletrônica, na qual foram calculados os índices $\mathrm{RDE}_{\text {total }}$ (Tabela 1);

c. os valores assim calculados foram plotados em planta, na metade aproximada do traçado de cada drenagem, possibilitando o traçado de curvas de isovalores de RDE (Figura 6). 


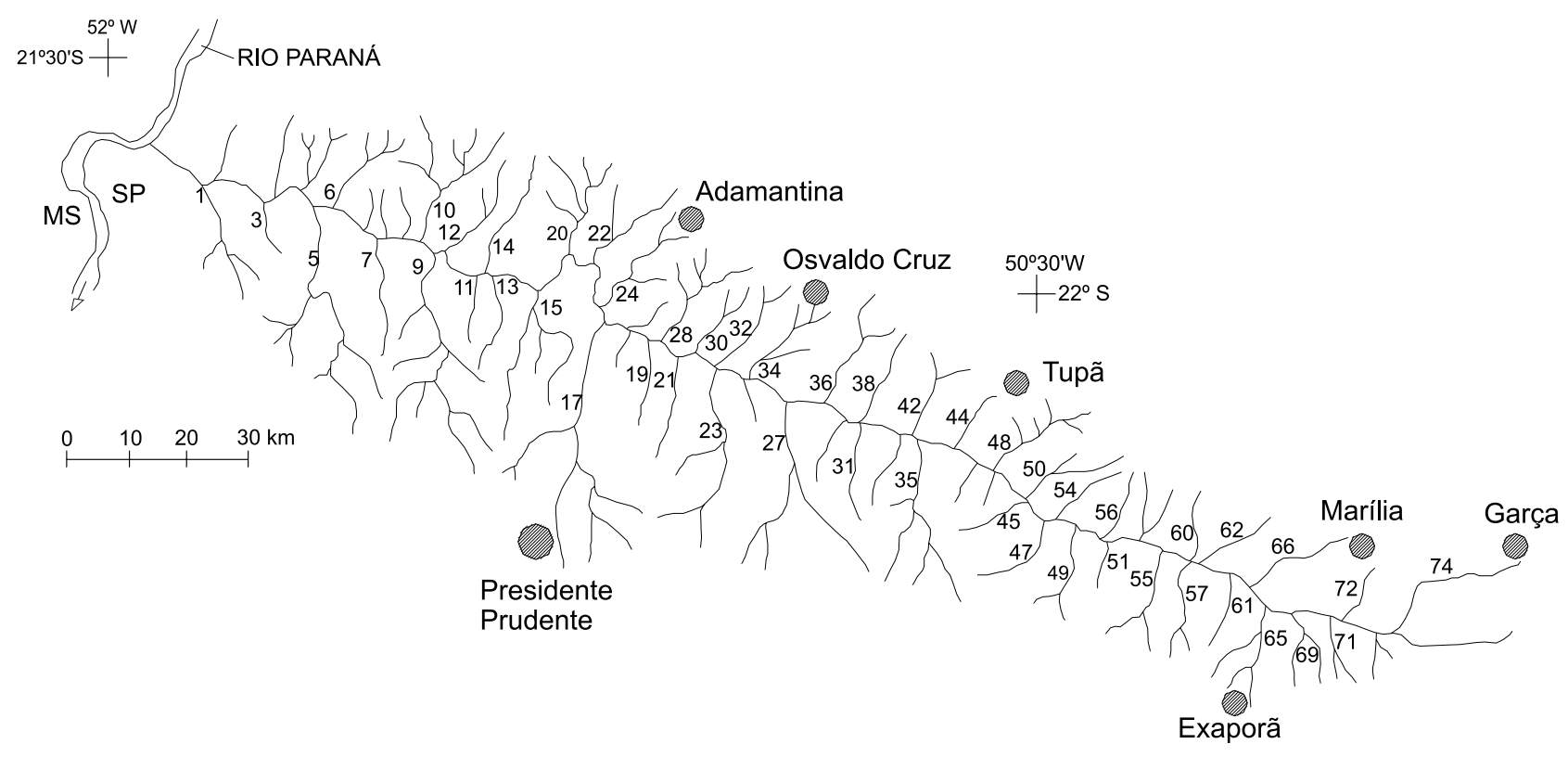

Figura 5. Principais elementos de drenagem na bacia hidrográfica do Rio do Peixe. Os números designam afluentes (cf. nomenclatura na Tabela 1).

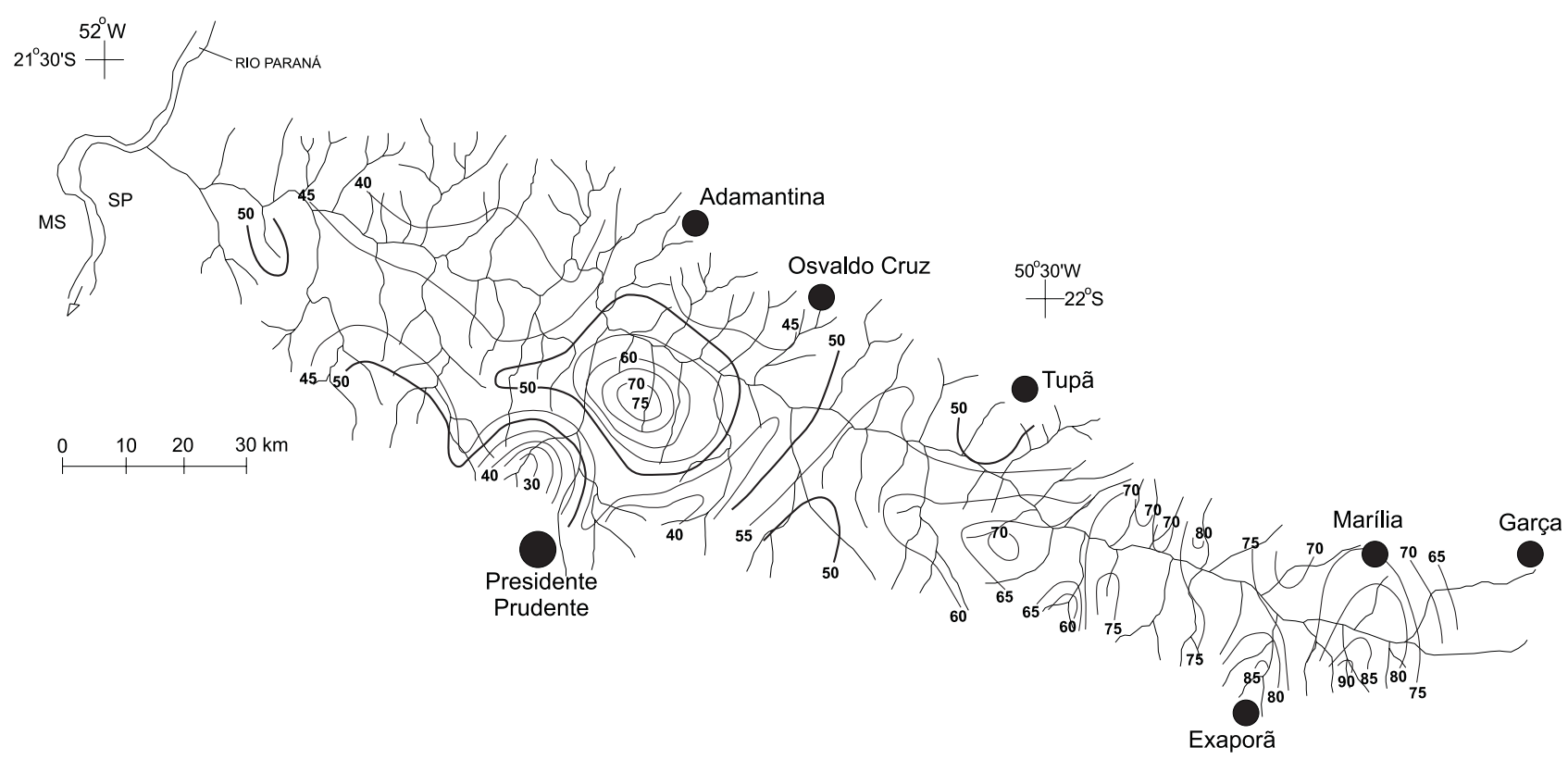

Figura 6. Mapa de contorno de isovalores de $\operatorname{RDE}_{\text {total }}$ na bacia do Rio do Peixe. 
Tabela 1. Relação Declividade-Extensão (RDE) para drenagens selecionadas da bacia do Rio do Peixe.

\begin{tabular}{|c|c|c|c|c|c|c|}
\hline Número & Drenagem & Extensão (km) & Cota cab. & Cota foz & Amplitude (m) & RDE \\
\hline 1 & Rib. das Pederneiras & 26,15 & 390 & 250 & 140 & 42,9 \\
\hline 3 & Cór. do Vargim & 16,20 & 390 & 250 & 140 & 50,3 \\
\hline 5 & Rib. Claro & 45,40 & 435 & 258 & 177 & 46,4 \\
\hline 6 & Cór. do Prado & 21,05 & 380 & 258 & 122 & 40,0 \\
\hline 7 & Rib. dos Índios & 23,40 & 415 & 262 & 153 & 48,5 \\
\hline 9 & Rib. do Taquaruçu & 50,30 & 460 & 279 & 181 & 46,2 \\
\hline 10 & Rib. dos Cainguangues & 28,10 & 400 & 278 & 122 & 36,6 \\
\hline 11 & Cór. Bonfim & 13,80 & 420 & 295 & 125 & 47,6 \\
\hline 12 & Cór. do Fogo & 23,50 & 410 & 281 & 129 & 40,9 \\
\hline 13 & Rib. Santo Expedito & 15,30 & 415 & 295 & 120 & 44,0 \\
\hline 14 & Rib. da Ilha & 32,00 & 435 & 295 & 140 & 40,4 \\
\hline 15 & Rib. do Montalvão & 34,05 & 475 & 296 & 179 & 50,7 \\
\hline 17 & Rib. do Mandaguari & 66,50 & 475 & 299 & 176 & 41,9 \\
\hline 19 & Rib. São José & 16,95 & 515 & 299 & 216 & 76,3 \\
\hline 20 & Rib. Santa Maria & 23,60 & 410 & 297 & 113 & 35,7 \\
\hline 21 & Rib. Coroados & 23,95 & 535 & 305 & 230 & 72,4 \\
\hline 22 & Rib. da Emboscada & 22,15 & 445 & 297 & 148 & 47,8 \\
\hline 23 & Rib. dos Guachos & 36,50 & 455 & 310 & 145 & 40,3 \\
\hline 24 & Rib. dos Ranchos & 29,30 & 465 & 299 & 166 & 49,1 \\
\hline 27 & Rib. da Confusão & 41,30 & 540 & 315 & 225 & 60,5 \\
\hline 28 & Rib. da Baliza & 24,65 & 440 & 301 & 139 & 43,4 \\
\hline 30 & Rib. dos Macacos & 21,40 & 450 & 307 & 143 & 46,7 \\
\hline 31 & Rib. Marra Mansa & 18,60 & 495 & 322 & 173 & 59,2 \\
\hline 32 & Rib. do Canguçú & 24,60 & 455 & 307 & 148 & 46,2 \\
\hline 34 & Rib. da Negrinha & 22,00 & 455 & 313 & 142 & 45,9 \\
\hline 35 & Rib. Francisco Padilha & 36,15 & 555 & 330 & 225 & 62,7 \\
\hline 36 & Rib. da Onça & 24,60 & 480 & 319 & 161 & 50,3 \\
\hline 38 & Cór. da Fortuna & 18,60 & 485 & 322 & 163 & 55,8 \\
\hline 42 & Rib. da Copaíba & 20,40 & 480 & 329 & 151 & 50,1 \\
\hline 44 & Rib. Santa Terezinha & 20,20 & 480 & 332 & 148 & 49,2 \\
\hline 45 & Cór. Taquara Branca & 18,95 & 550 & 342 & 208 & 70,7 \\
\hline 47 & Rib. do Cristal & 24,05 & 555 & 344 & 211 & 66,3 \\
\hline 48 & Rib. das Pitangueiras & 25,00 & 500 & 337 & 163 & 50,6 \\
\hline 49 & Rib. do Hospital & 18,70 & 515 & 348 & 167 & 57,0 \\
\hline 50 & Rib. Aldeia Grande & 22,00 & 520 & 339 & 181 & 58,6 \\
\hline 51 & Rib. do Monjolinho & 18,80 & 575 & 354 & 221 & 75,3 \\
\hline 54 & Cór. Santo Antônio & 15,95 & 555 & 353 & 202 & 72,9 \\
\hline 55 & Rib. do Engano & 20,05 & 580 & 370 & 210 & 70,0 \\
\hline 56 & Rib. Macaúbas & 14,75 & 575 & 365 & 210 & 78,0 \\
\hline 57 & Rib. da Panela & 21,50 & 595 & 378 & 217 & 70,7 \\
\hline 60 & Rib. Guaiuvira & 15,35 & 600 & 377 & 223 & 81,7 \\
\hline 61 & Rib. Mumbuca & 15,30 & 595 & 400 & 195 & 71,5 \\
\hline 62 & Rib. do Futuro & 20,05 & 605 & 379 & 226 & 75,4 \\
\hline 65 & Rib. do Barreiro & 21,30 & 655 & 390 & 265 & 86,6 \\
\hline 66 & Rib. da Barra Grande & 29,60 & 620 & 388 & 232 & 68,5 \\
\hline 69 & Rib. Três Lagoas & 16,10 & 580 & 395 & 185 & 66,6 \\
\hline 71 & Rib. do Arrependido & 14,90 & 660 & 399 & 261 & 96,6 \\
\hline 72 & Cór. do Barbosa & 14,65 & 635 & 401 & 234 & 87,2 \\
\hline 74 & Rib. da Garça & 38,70 & 650 & 420 & 230 & 62,9 \\
\hline
\end{tabular}

Obs: 1) os números de identificação das drenagens são aqueles plotados na Figura 5. 2) cab. = cabeceira. 


\section{Análise e interpretação dos índices}

Depreende-se da observação da Figura 6, que os valores de RDE tendem a diminuir ao longo da bacia do Rio do Peixe, com os maiores valores se concentrando no alto vale. Um perfil longitudinal desta bacia hidrográfica, apondo-se no eixo das ordenadas os valores de RDE obtidos das curvas da Figura 6, possibilita, de modo simples e efetivo, traçar as principais zonas anômalas (Figuras 7 e 8), acrescentando-se algumas informações de campo (fonte: Etchebehere, 2000) que podem subsidiar a interpretação neotectônica.

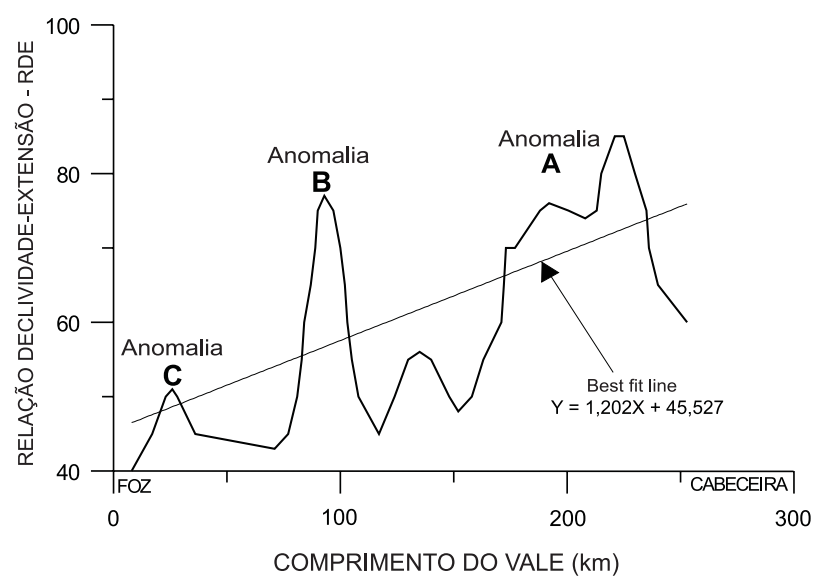

Figura 7. Distribuição de valores RDE ao longo de um perfil longitudinal aproximado do vale do Rio do Peixe, mostrando as três principais anomalias (delineadas por valores de RDE acima da linha de melhor ajuste - best fit line).

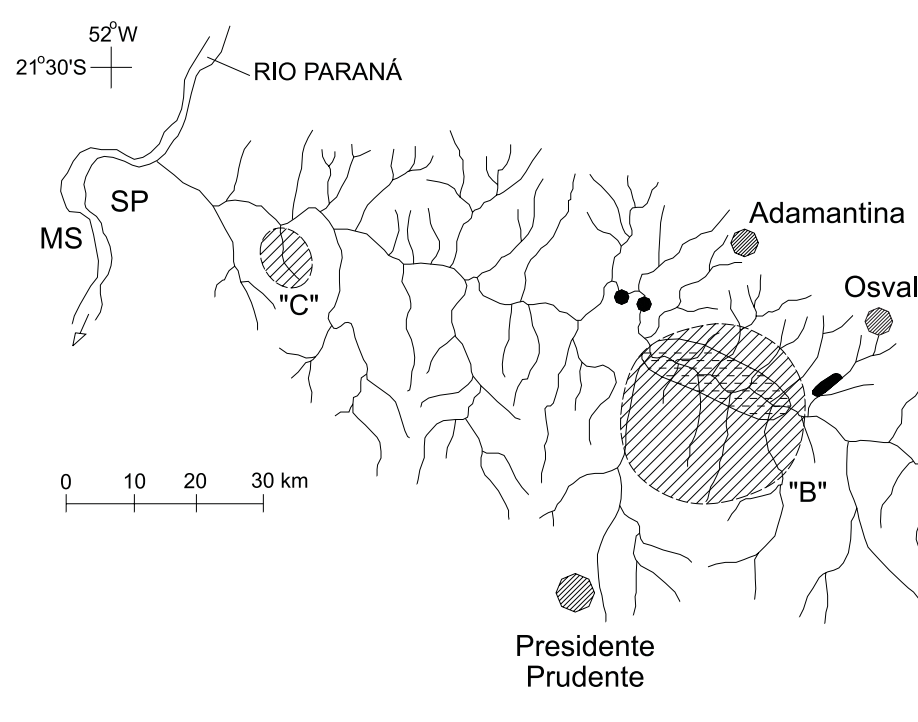

- Alinhamento de pontos-jusante de vales suspensos

- Feições de liquefação (vulcões de areia e diques e sills com espessuras superiores a $30 \mathrm{~cm}$ )

\section{Zona de concentração de cascalheiras eluvionares em} topos de morrotes

Anomalia morfométrica (RDE regional) cf. limites delineados na Figura 7

Figura 8. Comparação das principais anomalias de RDE com informações de campo (alinhamentos de pontos-jusante de vales suspensos; ocorrência de estruturas de liquefação originadas por sismos de magnitude expressiva $(>5,5)$; e zona de concentração de cascalheiras em topo de morrotes. Informações de campo segundo Etchebehere (2000)). 
Analisando-se estas três figuras (6 a 8), pode-se observar, além da tendência geral de diminuição dos valores de RDE rumo à foz do Rio do Peixe, três áreas anômalas, quais sejam:

1. a primeira anomalia (A) situa-se a sul da cidade de Marília, abrange cerca de $80 \mathrm{~km}$ ao longo do vale do rio, e inclui os valores mais elevados de RDE, com terminações abruptas nas duas extremidades. Abrange o alto vale do Rio do Peixe, região caracterizada por elevada densidade de drenagem, orlada pelas escarpas do Planalto de Marília-Exaporã. Abarca também expressiva concentração de vales suspensos ( $c f$. alinhamentos de pontos jusante de vales suspensos na Figura 8), além de conspícuas ocorrências de estruturas de liquefação (Etchebehere e Saad, 2002). Esta anomalia está contida, aproximadamente, no âmbito da sutura Ribeirão Preto;

2. a segunda anomalia (B) é a de maior realce, pois, embora seus valores não sejam os mais elevados (o "ápice" da anomalia tem valor de RDE ao redor de 75), está situada na porção mais a jusante do que a anomalia A (região de predomínio de menores índices de RDE), mostrando um nítido contraste com as circunvizinhanças. O trecho do Rio do Peixe envolvido situa-se, grosso modo, entre os quilômetros 200 e 230 de extensão do curso d'água, contados a partir da nascente. Nesta área, de acordo com Etchebehere (2000), a densidade de drenagem é bastante elevada, os depósitos de terraço são comuns, como também são freqüentes as cascalheiras em topos de elevações e estruturas de liquefação, especialmente do tipo extrusivo (vulcões e prismas de areia, $c f$. Etchebehere e Saad, 2002); aluviões recentes são escassos, e o talvegue do Rio do Peixe mostra-se estreito, fazendo com que diversos de seus afluentes tenham desembocadura em pequenas cascatas ("Setor dos Saltos" cf. CGC 1913). Os terraços, inclusive, chegam a se apresentar em diversos níveis topográficos (situações localizadas), o que, como já referido, poderia caracterizar um comportamento tectônico local diferenciado, configurando episódios de soerguimento (blocos?). Tal anomalia demarca, com precisão, a área de abrangência da chamada sutura Presidente Prudente e poderia, inclusive, servir como um delimitador, em planta, da referida feição tectônica no vale do Rio do Peixe;

3. a terceira zona anômala (C) é a de menor expressão, ocupando uma região da bacia onde predominam terrenos de feições geomórficas muito suaves, com ampla planície aluvionar atual do Rio do Peixe. Trata-se de uma área com baixa densidade de drenagem, com depósitos de terraço contínuos, que se interligam com acumulações de mesma natureza na margem esquerda do rio Paraná; tendo sido interpretada por Etchebehere (2003) como um setor subsidente, em formato de cunha, limitado por lineamentos de direções WNW-ESE e NW-SE. Não se dispõe de dados de campo para esta zona, mas não se pode descartar uma conexão com a sutura Três Lagoas, até mesmo pela proximidade com a anomalia geomorfológica da foz do Rio do Peixe, interpretada por Nakasu (1998) como palco de um intricado jogo de falhas com movimentação neotectônica e reflexos na própria geomorfologia da área.

Cotejando-se este quadro com o perfil longitudinal do Rio do Peixe, pode-se observar que as anomalias A e B correspondem a dois "ressaltos" convexos no referido perfil, respectivamente ao redor dos quilômetros 100 e 280 (Figura 3). A zona anômala $\mathrm{C}$ não aparece no perfil, possivelmente devido ao pequeno porte, comparada com as duas primeiras anomalias, e por estar associada a um afluente da margem esquerda do Peixe, em seu baixo curso, e não diretamente a ele. Seja como for, os perfis longitudinais afiguram-se como ferramentas para uma rápida detecção das principais anomalias e o índice RDE permite melhor definição e configuração em planta, além de possibilitar uma adequada comparação entre as diversas anomalias.

Dois alinhamentos de pontos-jusante de vales suspensos e uma pequena zona de ocorrência de cascalheiras eluvionares em topos de morrotes, situados junto ao Rio do Peixe, a sudoeste de Tupã, não foram abrangidos pelas anomalias de RDE. É possível que o caráter regional aqui adotado (valores de RDE plotados na metade do curso d'água) não possibilite a detecção de anomalias pequenas. Outra possibilidade é a de que esta área não esteja mais sendo submetida a soerguimento, remanescendo algumas marcas de atividade tectônica pretérita, ainda não eliminadas pelos processos de dinâmica superficial.

Com base nas informações geológicas já adiantadas na descrição acima, e levando-se em conta as observações de Burnett e Schumm (1983); Ouchi (1985); Phillips e Schumm (1987) e Etchebehere e Saad (1999), pode-se interpretar que as anomalias de RDE devem refletir áreas de soerguimento mais acentuado. Nesta circunstância, os rios aceleram o processo de entalhe, com aprofundamento do talvegue, gerando, em um primeiro momento, depósitos de terraço, os quais, a continuar o processo de soerguimento, também serão erodidos na seqüência. No caso específico da bacia do Rio do Peixe, é bastante clara a correlação entre estas anomalias e as áreas de degradação de terraços, bem como a associação com cascalheiras em topos de morro, aqui interpretadas como de natureza eluvial (residuum), e com as suturas Ribeirão Preto e Presidente Prudente, e com o lineamento Guapiara. A prevalecer a tese subjacente à metodologia dos índices RDEs, tem-se que estas feições regionais estariam sendo submetidas a movimentações recentes, configurando, ao lado da sismicidade, evidências de atuação de processos neotectônicos. 


\section{CONSIDERAÇÕES FINAIS}

O emprego de métodos de análise neotectônica baseados em parâmetros de morfometria fluvial não é propriamente uma novidade, conquanto não utilizado com freqüência na literatura geológica brasileira. Considerando que os cursos d'água, sempre sensíveis a qualquer processo deformativo de seus leitos, modificam as suas características morfométricas para atingir as suas necessárias condições de equilíbrio, tem-se em mãos uma ferramenta de análise bastante útil em estudos neotectônicos.

Saliente-se, da mesma forma, que as condições fisiográficas do oeste paulista (relevo suave, intemperismo profundo) dificultam, sobremaneira, a deteç̧ão, na paisagem, de elementos indicadores da atuação de processos neotectônicos. Tais dificuldades abrem espaço para a busca de abordagens não-convencionais de análise morfotectônica, como pode ser considerado o método aqui empregado, de aplicação ainda pouco difundida na região sudeste.

Os resultados alcançados pela aplicação do índice RDE no vale do Rio do Peixe podem ser considerados auspiciosos, sendo que as anomalias morfométricas delineadas devem representar áreas sujeitas a movimentações relacionadas a processos neotectônicos, possivelmente de natureza ascensional, mostrando uma consistência bastante expressiva com elementos geológicos disponíveis.

A técnica de análise morfométrica dos índices RDEs de drenagem se afigura como simples, rápida e apropriada para avaliações de cunho regional, permitindo definir setores anômalos em cada drenagem e selecionar, dessa forma, alvos para investigações de campo (follow up), sendo importante salientar que ela demanda, para sua aplicação, apenas uma base plani-altimétrica de boa qualidade e uma calculadora para a confecção das planilhas. Perfis longitudinais dos rios afiguram-se como ferramentas para uma avaliação preliminar do quadro de anomalias ao longo dos principais cursos d'água. Por sua vez, o índice RDE permite melhor definição dessas anomalias, possibilitando configurá-las em planta, estabelecer comparações entre elas, e gerar, inclusive, um mapa-síntese acerca do quadro deformacional de uma dada bacia hidrográfica (isodefs).

\section{REFERÊNCIAS BIBLIOGRÁFICAS}

BJORNBERG, A. J. S. Contribuição ao estudo do Cenozóico paulista: tectônica e sedimentologia. São Carlos. 1969a. 128 f. Tese (Provimento do cargo de Professor) - Universidade de São Paulo, São Carlos.

BJORNBERG, A. J. S. Critério geomorfológico para determinação de áreas falhadas. In: CONGRESSO BRASILEIRO DE GEOLOGIA, 23., 1969b. Salvador. Resumo das conferências e das comunicações... Salvador: SBG, 1969.p. 65-66.

BJORNBERG, A. J. S. Microestrutura dos solos. In: NEGRO Jr. et al. (Eds.) Solos da cidade de São Paulo. São Paulo: ABMS/ABEF, 1992. p. 98-109.

BOYD, K. F.; SCHUMM, S. A. Geomorphic evidence of deformation in the Northern part of the New Madrid seismic zone. In: SHEDLOCK, K. M.; JOHNSTON, A. C. (Eds.) Investigations of the New Madrid seismic zone. USGS, 1995. 35 p. (U.S. Geological Survey Prof. Paper, 1538-R).

BURNETT, A. W.; SCHUMM, S. A. Alluvial river response to neotectonic deformation in Louisiana and Mississippi. Science, v. 222, p. 49-50, 1983.

COMISSÃO GEOGRAPHICAEGEOLOGICADOESTADO DE SÃO PAULO. Exploração do Rio do Peixe. 2. ed. São Paulo: Typ. Brazil de Rothschild \& Cia., 1913.39 p.

CHRISTOFOLETTI, A. Análise morfométrica das bacias hidrográficas. Notas Geomorfológicas, v. 9, n. 18, p. 35-64, 1969.

DEPARTAMENTO DE ÁGUAS E ENERGIA ELÉTRICA. Estudo de águas subterrâneas - Regiões Administrativas 10 e 11 - Presidente Prudente e Marília. São Paulo: DAEE. 1979.3v.

DEFFONTAINES, B.; CHOROWICZ, J. Principles of drainage basin analysis from multisource data: application to the structural analysis of the Zaire Basin. Tectonophysics, v. 194, p. 237-263, 1991.

ETCHEBEHERE, M. L. C. Neotectônica e sedimentação cenozóica na bacia hidrográfica do Rio do Peixe, banda ocidental do Estado de São Paulo. In: SEMINÁRIO DE PÓS-GRADUAÇÃO EM GEOCIÊNCIAS, 1., 1996. Rio Claro. Projetos em Andamento... Rio Claro: IGCE-UNESP, 1996. p. 292-294.

ETCHEBEHERE, M. L. C. Utilização de parâmetros morfométricos de drenagem para delinear deformações crustais - Aplicação no vale do Rio do Peixe, SP. 1999. f. 44-111. Exame de Qualificação (Doutorado) - Instituto de Geociências e Ciências Exatas, Universidade Estadual Paulista, Rio Claro.

ETCHEBEHERE, M. L. C. Terraços neoquaternários no vale do Rio do Peixe, Planalto Ocidental Paulista: implicações estratigráficas e tectônicas. 2000. 2v. Tese (Doutorado) - Instituto de Geociências e Ciências Exatas, Universidade Estadual Paulista, Rio Claro.

ETCHEBEHERE, M. L. C.; SAAD, A. R. Relação Declividade / Extensão de Curso (RDE) aplicada à detecção de deformações neotectônicas regionais na bacia hidrográfica do Rio do Peixe, SP. In: SIMPÓSIO DE GEOLOGIADO SUDESTE, 6., 1999. São Pedro. Boletim de Resumos... Rio Claro: SBG-SP/RJ-ES/UNESP, 1999. p. 93.

ETCHEBEHERE, M. L. C.; SAAD, A. R. Feições de liquefação no vale do Rio do Peixe, Região Ocidental Paulista - 
Implicações paleossísmicas. Geociências, v. 21, n. 1/2, p. 43-56, 2002.

ETCHEBEHERE, M. L. C. et al. Feições de liquefação em sedimentos cenozóicos no vale do Rio do Peixe, região ocidental paulista: implicações neotectônicas. In: CONGRESSO BRASILEIRO DE GEOLOGIA, 40., 1998. Belo Horizonte. Anais... Belo Horizonte: SBG, 1998. p. 80.

ETCHEBEHERE, M. L. C. et al. Detecção de deformações neotectônicas no vale do Rio do Peixe, região ocidental paulista, mediante aplicação de índices RDE em segmentos de drenagem. (Artigo em preparação).

FULFARO, V. J.; BARCELOS, J. H. Fase Rifte na Bacia Sedimentar do Paraná: a Formação Caiuá. Geociências, Rio Claro, v. 12, n. 1, p. 33-45, 1993.

FULFARO, V. J. et al. Bacia Caiuá: uma nova bacia cretácica na Bacia do Paraná. In: SIMPÓSIO SOBRE O CRETÁCEO DO BRASIL, 5., 1999. Serra Negra. Boletim... Serra Negra: UNESP, 1999. p. 439-442.

HACK, J. T. Interpretation of erosional topography in humid temperate regions. American Journal of Science, v. 258 A, p. 80-97, 1960.

HACK, J. T. Stream-profile analysis and stream-gradient index. Journal of Research of the United States Geological Survey, v. 1, n. 4, p. 421-429, 1973.

HASUI, Y. Neotectônica e aspectos fundamentais da tectônica ressurgente no Brasil. In: WORKSHOP SOBRE NEOTECTÔNICA E SEDIMENTAÇÃO CENOZÓICACONTINENTALNOSUDESTEBRASILEIRO, 1., 1990. Belo Horizonte. Boletim... Belo Horizonte: SBG-MG, 1990, p. 1-31.

HORTON, R. E. Erosional development of streams and their drainage basins: hydrophysical approach to quantitative morphology. Geological Society of America Bulletin., v. 56, p. 275-370, 1945.

HOWARD, A. D. Drainage analysis in geologic interpretation: A summary. AAPG Bulletin, v. 51, p. 2246-2259, 1967.

INSTITUTO DE PESQUISAS TECNOLÓGICAS. Compartimentação estrutural e evolução tectônica do Estado de São Paulo. São Paulo: IPT, 1989. 2 v. (Relatório 27.394).

INSTITUTO DE PESQUISAS TECNOLÓGICAS Sismotectônica e dinâmica superficial na área do Complexo Hidrelétrico Canoas. São Paulo: IPT, 1992. 4 v. (Relatório 30.924).

JUSTUS, J. O. Subsídios para interpretação morfogenética através da utilização de imagens de radar. 1985. $204 \mathrm{f}$. Dissertação (Mestrado) - Universidade Federal da Bahia, Salvador.

KELLER, E. A.; PINTER, N. Active tectonics - eartquakes, uplift, and landscape. New Jersey: Prentice Hall, 1996. 338 p.
LEOPOLD, L. B.; BULL, W. B. Base level, aggradation and grade. Proceedings of the American Philosophical Society, v. 123, p.168-202, 1979.

LEOPOLD, L. B.; LANGBEIN, W. B. The concept of entropy in landscape evolution. U. S. Geological Survey Professional Paper, n. 500-A, p. 1-20, 1962.

MACKIN, J. H. Concept of the graded river. Geological Society of America Bulletin, v. 59, p. 463-512, 1948.

MARPLE, R. T.; TALWANI, P. Evidence of possible tectonic upwarping along the South Carolina coastal plain from an examination of river morphology and elevation data. Geology, v. 21, p. 651-654, 1993.

MAYER, L. Quantitative analysis of landforms: A way to delineate active tectonic structures. Oxford: Geomorphology Laboratory - Department of Geology, 1992. 48 p. (Annual Technical Report).

McKEOWN, F. A. et al. Analysis of stream-profile data and inferred tectonic activity, Eastern Ozark Mountains region. U. S. Geological Survey Bulletin, n. 1807, p. 1-39, 1988.

MERRITS, D.; HESTERBERG, T. Stream networks and longterm surface uplift in the New Madrid seismic zone. Science, v. 265, p.1081-1084, 1994.

MERRITS, D.; VINCENT, K. R. Geomorphic response of coastal streams to low, intermediate, and high rates of uplift, Mendocino triple junction region, northern California. Geological Society of America Bulletin., v. 101, p. 1373-1388, 1989.

MIOTO, J. A. Sismicidade e zonas sismogênicas do Brasil. 1993. 2v. Tese (Doutorado) - Instituto de Geociências e Ciências Exatas, Universidade Estadual Paulista, Rio Claro.

MIOTO, J. A. Excertos sobre risco sísmico no Estado de São Paulo. Revista UnG - Série Geociências, v. 1, n. 3, p. 18-23, 1996.

MORAES REGO, L. F. Notas sobre a geomorfologia de São Paulo e sua gênesis. São Paulo: IAG, 1932. 43 p.

NAKASU, L. Recursos minerais do rio Paraná a montante de Guaíra. 1998. 212 f. Tese (Doutorado) - Instituto de Geociências e Ciências Exatas, Universidade Estadual Paulista, Rio Claro.

OUCHI, S. Response of alluvial rivers to slow active tectonic movement. Geological Society of America Bulletin., v. 96, p. 504-515, 1985.

PHILLIPS, L. F.; SCHUMM, S. A. Effect of regional slope on drainage networks. Geology, v. 15, p. 813-816, 1987.

RHEA, S. Evidence for uplift near Charleston, South Carolina. Geology, v. 17, p. 311-315, 1989.

RICCOMINI, C. Tectonismo gerador e deformador dos depósitos sedimentares pós-gondvânicos da porção centro-oriental do Estado de São Paulo e áreas vizinhas. 1995. 100 f. Tese de Livre Docência - Instituto de 
Geociências da Universidade de São Paulo, São Paulo.

RICCOMINI, C. Arcabouço estrutural e aspectos do tectonismo gerador e deformador da Bacia Bauru no Estado de São Paulo. Revista Brasileira de Geociências, v. 27, n. 2, p. 153-162, 1997.

RIVEREAU, J. C. Notas de aula do curso de fotointerpretação. Curitiba: Inst. Geol. UFP, 1969.93p.

RODRIGUEZ, S. K. Neotectônica e sedimentação quaternária na região da "Volta Grande" do rio Xingu, Altamira, PA. 1993. 106 f. Dissertação (Mestrado) - Instituto de Geociências, Universidade de São Paulo, São Paulo.

RODRIGUEZ, S. K.; SUGUIO, K. Gradientes hidráulicos das drenagens de $2^{a}$ ordem: uma contribuição para os estudos de neotectônica da "Volta Grande" do rio Xingu, Altamira-PA. In: CONGRESSO BRASILEIRO DE GEOLOGIA, 37., 1992. São Paulo. Resumos expandidos... São Paulo: SBG 1992. p. 598-600.

SAAD, A. R. Análise da produção técnico-científica. 1997. 150 f. Texto (Concurso para obtenção do título de LivreDocente) - Instituto de Geociências e Ciências Exatas, Universidade Estadual Paulista, Rio Claro.

SCHUMM, S. A. River response to baselevel change: Implications for sequence stratigraphy. Journal of Geology, v. 101, p. 279-294, 1993.

SCHUMM, S. A.; SPITZ, W. J. Geological influences on the Lower Mississippi River and its alluvial valley. Engineering Geology, v. 45, p. 245-261, 1996.

SEEBER, L.; GORNITZ, V. River profiles along the Himalayan arc as indicators of active tectonics. Tectonophysics, v. 92, p. 335-367, 1983.

SHEPHERD, R .G. Regression analysis of river profiles. Journal of Geology, v. 93, p. 377-384, 1985.

SECRETARIADO MEIO AMBIENTE. Gestão das águas: 6 anos de percurso. São Paulo: SMA - Secretaria de Recursos Hídricos, Saneamento e Obras, 1997. 2 cadernos, $128 \mathrm{p}$.

SNOW, R S.; SLINGERLAND, R. L. Mathematical modeling of graded rivers profiles. Journal of Geology, v. 95, n. 1, p. 15-33, 1987.

SPITZ, W. J.; SCHUMM, S. A. Tectonic geomorphology of the Mississippi Valley between Osceola, Arkansas, and Friars Point, Mississippi. Engeenring Geology, v. 46, p. 259-280, 1997.

STRAHLER, A. N. Dynamic basis of geomorphology. Geological Society of American Bulletin, v. 63, p. 923-938, 1952a.

STRAHLER, A. N. Hypsometric (area-altitude) analysis of erosional topography. Geological Society of America Bulletin., v. 63, p. 1117-1142, 1952b.

TAKIYA, H. Estudo da sedimentação neogênicoquaternária no município de São Paulo: caracteriza- ção dos depósitos e suas implicações na geologia urbana. 1997. 152 f. Tese (Doutorado) - Instituto de Geociências, Universidade de São Paulo, São Paulo.

TANNER, W. F. The river profiles. Journal of Geology, v. 79, p. 482-492, 1971.

VOLKOV,N. G; SOKOLOVSKY,I.L.; SUBBOTIN,A. I.Effect of recent crustal movements on the shape of longitudinal profiles and water levels in rivers. In: INTERNATIONAL SYMPOSIUM ON RIVER MECHANICS, 1967. Bern. Proceedings... Bern: International Union of Geodesy and Geophysics, 1967. p. 105-116.

WESCOTT, W. A. Geomorphic thresholds and complex response of fluvial systems - Some implications for sequence stratigraphy. AAPG Bulletin, v. 77, n. 7, p. 1208-1218, 1993.

ZERNITZ, E. R. Drainage patterns and their significance. Journal of Geology, v. 40, n. 6, p. 498-521, 1932. 